\title{
Cartographic Visualisation of Spatial Phenomenons within Creative Industries
}

\author{
Rostislav Netek $^{\mathrm{a}, *}$ \\ a Dept.of Geoinformatics, Palacký University Olomouc; rostislav.netek@ upol.cz; \\ * Corresponding author
}

Keywords: brain drain, creative industries, spatial analysis, visualisation

\begin{abstract}
:
The paper discusses the issue of spatial visualisation within the topic of cultural and creative industries. Phenomenons such as spatial distribution, spatial evaluation of influence cultural subjects to the city environment, brain-drain and brain-gain of actors involved in the creative industries are demonstrated on the example of the Olomouc region, Czech Republic. It is based on spatial mapping of the creative industries in the region during the last decade. Based on the identification and collection of spatial data, over 1200 active subjects were identified in both spatial and non-spatial database. The general goal of the research is the find out the motivations of actors and talents within creative industries to leave from (brain-drain) or to come into (brain-gain) Olomouc region.

The article focuses on the proposal of a strategy for strengthening the segment especially by spatial analysis and visualisation of the phenomenons. It aims to identify brain drain - talent and capital exodus with a purpose to propose stable position of creative industries within the region. The set of proposed measures and recommendations are primarily based on geographic and geoeconomic analyses supported by cartographic outputs. It offers to municipalities applicable tools to reduce side effects and identification of creative hubs, it enables systemic measures for recruitment and improvement of conditions for human capital development and acquisition. The presented paper describes the cartographic methods, procedures, spatial analyzes and map outputs achieved during the research.
\end{abstract}

\section{Acknowledgements}

This paper was supported by the project " Spatial Differentiation and Visualisation of Geodemographic Processes with a Focus on Households in an Ageing Society in the Czech Republic " (reg. num. 18-12166S) of Czech Science Foundation. 